\title{
Genetic diversity based on SSR analysis of the cultured snakehead fish, Channa argus, (Channidae) in China
}

S.-R. Zhu ${ }^{1,2}, \mathrm{~J}-\mathrm{L} . \mathrm{Li}^{1}, \mathrm{~N} . \mathrm{Xie}^{3}, \mathrm{~L}-\mathrm{M} \cdot \mathrm{Zhu}^{3}, \mathrm{Q} \cdot \mathrm{Wang}^{2}$ and $\mathrm{G}-\mathrm{H} \cdot \mathrm{Yue}{ }^{4}$

${ }^{1}$ Key Laboratory of Freshwater Aquatic Genetic Resources Certified by Ministry of Agriculture, Shanghai Ocean University, Shanghai, China ${ }^{2}$ Department of Biology, East China Normal University, Shanghai, China ${ }^{3}$ Institute of Fisheries, Hangzhou Academy of Agriculture Science, Hangzhou, China

${ }^{4}$ Molecular Population Genetics Group, Temasek Life Sciences Laboratory, National University of Singapore, Singapore, Singapore

Corresponding author: J.-L. Li

E-mail: j1li2009@126.com

Genet. Mol. Res. 13 (3): 8046-8054 (2014)

Received December 11, 2012

Accepted May 13, 2013

Published February 13, 2014

DOI http://dx.doi.org/10.4238/2014.February.13.6

ABSTRACT. The snakehead fish Channa argus is an important food
fish in China. We identified six microsatellite loci for $C$. argus. These
six microsatellite loci and four other microsatellite markers were used to
analyze genetic diversity in four cultured populations of $C$. argus (SD, JX,
$\mathrm{HN}$, and ZJ) and determine their relationships. A total of 154 alleles were
detected at the 10 microsatellite loci. The average expected and observed
heterozygosities varied from $0.70-0.84$ and $0.69-0.83$, respectively, and
polymorphism information content ranged between 0.66 and 0.82 in
the four populations, indicating high genetic diversity. Population JX
deviated from mutation-drift equilibrium and may have experienced a
recent bottleneck. Analysis of pairwise genetic differentiation revealed
$F_{\mathrm{ST}}$ values that ranged from 0.028 to 0.100 , which indicates a moderate
level of genetic differentiation. The largest distances were observed 
between populations $\mathrm{HN}$ and $\mathrm{SD}$, whereas the smallest distances were obtained between populations HN and JX. Genetic clustering analysis demonstrated that the ZJ and $\mathrm{HN}$ populations probably share the same origin. This information about the genetic diversity within each of the four populations, and their genetic relationships will be useful for future genetic improvement of $C$. argus through selective breeding.

Key words: Channa argus; Population genetic differentiation; Microsatellite;

\section{INTRODUCTION}

Channa argus, commonly called the snakehead fish, belongs to the family Channidae; it is native to eastern Russia and China, as well as parts of North Korea (Courtenay and Williams, 2004). Former Soviet Republics of Uzbekistan, Kazakhstan and Turkmenistan have experienced relatively recent introductions of snakehead fish (Amanov, 1974; Dukravets and Machulin, 1978). In many areas of the world, the snakehead fish is a cultured freshwater fish species, which grows very fast and has a high nutritious and economic value, especially in China (Guo et al., 2004). However, the wild snakehead fish has declined sharply because of overfishing and improper management (Li and Yang, 1998). In this regard, the snakehead fish breeding industry has become very important.

Identifying population structure is one of the cornerstones of aquaculture population assessment (Begg and Waldman, 1999). Microsatellites (simple sequence repeats, SSRs) are a form of repetitive DNA discovered in the 1980s (Tautz and Renz, 1984). Their repeat numbers are variable, which makes microsatellites polymorphic. Characterized by codominant inheritance, high polymorphism and good reproducibility, microsatellites have become instrumental as genetic markers in areas such as population genetics, parentage assignment, marker-assisted breeding and phylogenetic evolution (Liu and Cordes, 2004; Yang et al., 2008; Liu et al., 2009). In addition, SSRs could help to assess the genetic and selective breeding of snakehead fish population.

In the present study, eight wild northern snakehead populations were analyzed using five microsatellite loci (Zhuo et al., 2012). Here, we report the isolation and characterization of five polymorphic microsatellite loci from the $C$. argus genome and one microsatellite locus from the C. maculate genome, and investigation of spatial genetic structure, interpopulation diversity and population genetic differentiation of four cultured $C$. argus populations, which will provide additional insight and help to facilitate the selective breeding of $C$. argus populations.

\section{MATERIAL AND METHODS}

\section{Sample collection and DNA extraction}

In China, Shandong, Jiangxi, Hunan, and Zhejiang are the major breeding provinces for the snakehead fish (Li and Yang, 1998). Places in these provinces, namely Luqiao in Shandong, Wujia in Jiangxi, Ruanjiang in Hunan, and Yuhang in Zhejiang, have a long history of breeding snakehead on a large scale (Li and Yang, 1998; Zhu et al., 2011). Sixty cultured $C$. argus specimens were respectively collected from these four areas (Table 1). Pectoral fins 
were collected from each fish and preserved in 95\% alcohol. Genomic DNA was extracted from one individual by the standard phenol-chloroform extraction method (Sambrook and Russell, 2001).

Table 1. Sampling sites and sample sizes of Channa argus used in the experiment.
\begin{tabular}{lllc}
\hline Stock & Sampled site & Location & Sample No. \\
\hline SD & Luqiao, Shandong & $34^{\circ} 89^{\prime} \mathrm{N} 117^{\circ} 08^{\prime} \mathrm{E}$ & 60 \\
JX & Wujia, Jiangxi & $29^{\circ} 64^{\prime} \mathrm{N} 15^{\circ} 91^{\prime} \mathrm{E}$ & 60 \\
HN & Ruanjiang, Hunan & $28^{\circ} 61^{\prime} \mathrm{N} 112^{\circ} 85^{\prime} \mathrm{E}$ & 60 \\
ZJ & Yuhang, Zhejiang & $30^{\circ} 39^{\prime} \mathrm{N} 120^{\circ} 18^{\prime} \mathrm{E}$ & 60 \\
\hline
\end{tabular}

\section{Microsatellite isolation}

About $600 \mathrm{ng}$ genomic DNA was digested with MseI restriction enzyme (NEB) at $37^{\circ} \mathrm{C}$ for $2 \mathrm{~h}$. These fragments were ligated to $\mathrm{MseI}$ adapters and then amplified by PCR using $M s e$ I-N primers (5'-GATGAGTCCTGAGTAAN-3') following the program of $94^{\circ} \mathrm{C}$ for 4 min, 30 cycles of $94^{\circ} \mathrm{C}$ for $30 \mathrm{~s}, 53^{\circ} \mathrm{C}$ for $1 \mathrm{~min}$ and $72^{\circ} \mathrm{C}$ for $1 \mathrm{~min}$, and $72^{\circ} \mathrm{C}$ for $5 \mathrm{~min}$. The PCR products were then hybridized with biotinylated probe $(\mathrm{CA})_{15}$ in a $300-\mu \mathrm{L}$ hybridization solution ( $4 \mathrm{X} \mathrm{SSC}, 0.1 \%$ sodium dodecyl sulfate, $0.5 \mu \mathrm{M}$ probe) at $55^{\circ} \mathrm{C}$ for $30 \mathrm{~min}$. Subsequent probe-bound DNA fragments were enriched for CA repeats using streptavidin-coated magnetic beads (Promega, Shanghai, China) at room temperature for $30 \mathrm{~min}$, followed by two washing steps. Recovered DNA fragments were amplified with MseI-N primers as described above. The PCR products, after being purified with Gel Extraction kit (Tiangen), were ligated to pGEM-T vector (Promega) and transformed into Escherichia coli DH5 $\alpha$ competent cells (Tiangen). Fifty-five positive clones were picked out and tested by PCR using MseI-N primers.

Positive clones were sequenced on an ABI 3700 automated DNA Sequencer (Applied Biosystems Incorporation), of which 46 screened clones containing microsatellite repeats. Primers for these loci were designed with the PRIMER3 online software. A total of five primer pairs produced polymorphic DNA products from $C$. argus genome and one primer produced a polymorphic DNA product from C. maculata, including CHA7, CHA13, CHA25, CHA31, CHA41, and CHM9 (Table 2). In addition, we designed four primers according to the NCBI sequence from the C. argus genome, and they showed high polymorphism in C. argus (Table 2).

\section{Microsatellite genotyping}

All ten microsatellite loci that amplified specific products were selected for further investigation using fluorescently labeled probe (either 6-FAM or HEX) on 240 samples from four populations (SD, JX, HN and ZJ). The PCR amplifications were performed in a $25-\mu \mathrm{L}$ volume, including approximately $20 \mathrm{ng}$ genomic DNA, $0.2 \mathrm{mM}$ dNTPs, $1.5 \mathrm{mM} \mathrm{MgCl}, 0.5$ $\mu \mathrm{M}$ of each primer, and $1 \mathrm{U}$ Taq DNA polymerase (Tiangen). The amplification program included an initial denaturation at $94^{\circ} \mathrm{C}$ for 3 min and 35 cycles of $30 \mathrm{~s}$ at $94^{\circ} \mathrm{C}, 30 \mathrm{~s}$ at $50-64^{\circ} \mathrm{C}$ depending on the primer pair (Table 2) and $1 \mathrm{~min}$ at $72^{\circ} \mathrm{C}$, followed by a final extension step for $10 \mathrm{~min}$ at $72^{\circ} \mathrm{C}$. Fluorescent dye-labeled fragments were separated and analyzed using the ABI3730xl sequencer GeneMapper software (Lo and Yue, 2008). 
Table 2. Microsatellite marker primers and their repeat sequences used in the experiment.

\begin{tabular}{|c|c|c|c|c|}
\hline GenBank No. & Primer sequence (5'-3') & Size & Repeat motif & Annealing temp. \\
\hline $\begin{array}{l}\text { HM015826 } \\
\text { TLL01 }\end{array}$ & $\begin{array}{l}\text { F: CACTGGTCACTGTTGAAATCT } \\
\text { R: CAGCGAGTACAAAATTACAGC }\end{array}$ & $253-305$ & $(\mathrm{TACA})_{7}$ & 58 \\
\hline $\begin{array}{l}\text { TLL01 } \\
\text { HM015833 }\end{array}$ & $\begin{array}{l}\text { K: CAGLUAGIACAAAAI IACAGC } \\
\text { F: TGATTGGCCAAATGTCTG }\end{array}$ & $257-327$ & (TAGA) & 55 \\
\hline TLL02 & R: GGACGCACCACCTAGAGAAG & $251-321$ & $(1 \mathrm{AUA})_{32}$ & 35 \\
\hline HM015836 & F: ATGACAGTGTTCCTGCTCTATG & 273-329 & $(\mathrm{TAGA})_{12}$ & 56 \\
\hline TLL03 & R: GGTGCAACTTCCTCAGTGA & & & \\
\hline HM015842 & F: CACACCCAAAGGTTACACC & $326-418$ & $(\mathrm{TAGA})_{35}$ & 55 \\
\hline TLL04 & R: AATGTGGGCACTGATCTTC & & & \\
\hline GQ131294 & F: ATTGGGTGCTGCCATCATAC & $164-185$ & $(\mathrm{AC})_{22}$ & 60 \\
\hline CHA7 & R: GGAGGAAACGGTTTGACTGA & & & \\
\hline GQ131300 & F: GTTTCAAAGGTCGGGAGAGG & $221-258$ & $(\mathrm{AC})_{15}$ & 64 \\
\hline CHA13 & R: AGCAAAAGCATGATCCTTGG & & & \\
\hline HQ404179 & F: CCTGGCATCTTCGGTAAAAG & $241-280$ & $(\mathrm{TG})_{19}$ & 58 \\
\hline CHA25 & R: CTCCAAGGGCGAAAACTCTT & & & \\
\hline HQ404185 & F: CCTCTGATGCCCTTAGAGACA & $151-198$ & $(\mathrm{AC})_{31}$ & 60 \\
\hline CHA31 & R: TCAGACTTCGTCTGCACCAG & & & \\
\hline HQ404195 & F: TGCCAGTTTATTGGAAAGCA & $135-180$ & $(\mathrm{TG})_{5} \mathrm{TC}(\mathrm{TG})_{26}$ & 56 \\
\hline CHA41 & R: GTAGGCACCTCAGCCATGAT & & & \\
\hline HQ404206 & F: CGCAGCAAGTATCAGCAT & $142-165$ & $(\mathrm{GT})_{6} \mathrm{GC}(\mathrm{GT})_{9}$ & 58 \\
\hline CHM9 & R: GGTCCCAACTAGGAAGAAC & & & \\
\hline
\end{tabular}

\section{Data analysis}

The numbers of alleles $\left(N_{\mathrm{A}}\right)$ and effective alleles $\left(N_{\mathrm{E}}\right)$, observed heterozygosity $\left(H_{\mathrm{O}}\right)$, expected heterozygosity $\left(H_{\mathrm{E}}\right)$, and pairwise linkage or gametic phase disequilibrium were analyzed using GDA (Lewis and Zaykin, 2000). Polymorphic information content (PIC) was calculated using a formula (Botstein et al., 1980). Pairwise genetic differentiation $F$-statistics and analysis of molecular variance (AMOVA) were determined using ARLEQUIN 3.1 (Excoffier et al., 2005). Phylogenetic trees were constructed using $F_{\mathrm{ST}}$ genetic distance based on the unweighted pair group method with arithmetic averages (UPGMA). The genetic structure of different $C$. argus populations was analyzed using Structure 2.3 (Pritchard et al., 2000; Evanno et al., 2005). In the assumption populations menu, we set the assumed $\mathrm{K}$ value from 1 to 4.

\section{RESULTS}

\section{Genetic diversity}

There was significant variation in the 10 microsatellite loci in this study, with 154 different alleles in 240 individuals from four populations. The mean number of alleles observed over all markers in four populations was 15.40 . PIC showed that all 10 loci were highly informative (mean $=0.81 \pm 0.10) . H_{\mathrm{E}}$ and $H_{\mathrm{O}}$ varied 0.64-0.94 and 0.56-0.98, respectively, and PIC between 0.57 and 0.93 in 240 individuals. Among them, $N_{\mathrm{A}}, N_{\mathrm{E}}, H_{\mathrm{E}}$, and PIC of locus TLL04 were the highest. Allelic diversity $\left(N_{\mathrm{A}}\right.$ and $\left.N_{\mathrm{E}}\right)$ and gene diversity $\left(H_{\mathrm{E}}\right.$ and $\left.H_{\mathrm{O}}\right)$ of each locus in every population are shown in Table 3 . Due to the important parameters for measuring allele polymorphism, we used $H_{\mathrm{E}}$ and PIC to compare different population, and found that the mean $H_{\mathrm{E}}$ and PIC were highly informative. In the four populations, the ZJ population showed the highest $H_{\mathrm{O}}(0.83)$, followed by HN (0.79), JX (0.74), and SD (0.69) (Table 3). The highest estimates of $H_{\mathrm{E}}$ were obtained from ZJ (0.84), followed by HN (0.83), JX (0.80), and SD (0.70), 
while PIC was the highest in ZJ (0.82), followed by HN (0.81), JX (0.77), and SD (0.66). The allele equilibrium status of the four stocks was tested for Hardy-Weinberg equilibrium, and some microsatellites deviated significantly from Hardy-Weinberg equilibrium $(\mathrm{P}<0.05)$, such as CHM9 in the SD population, TLL01, CHA7, CHA13, CHA41, and CHM9 in the JX population, and TLLO1 and CHA25 in the HN population.

\begin{tabular}{|c|c|c|c|c|c|c|c|c|c|c|c|c|}
\hline Population & Index & $T L L O 1$ & TLLO2 & TLLO3 & TLL04 & CHA7 & CHA13 & CHA25 & СНА3I & CHA41 & СHM9 & Mean \\
\hline \multirow[t]{6}{*}{ SD } & $N_{\mathrm{A}}$ & 3 & 15 & 11 & 19 & 4 & 5 & 8 & 11 & 8 & 7 & 9.1 \\
\hline & $N_{\mathrm{E}}^{\mathrm{A}}$ & 1.9 & 7.4 & 4.2 & 3.9 & 2.2 & 2.0 & 4.1 & 4.9 & 5.2 & 3.1 & 3.9 \\
\hline & $H_{\mathrm{O}}^{\mathrm{E}}$ & 0.45 & 1.00 & 0.77 & 0.49 & 0.65 & 0.43 & 0.77 & 0.86 & 0.75 & 0.72 & 0.69 \\
\hline & $H_{\mathrm{E}}$ & 0.48 & 0.87 & 0.77 & 0.75 & 0.55 & 0.50 & 0.76 & 0.80 & 0.82 & 0.69 & 0.70 \\
\hline & $\begin{array}{l}\text { PIC } \\
\text { PIC }\end{array}$ & 0.38 & 0.85 & 0.73 & 0.74 & 0.50 & 0.46 & 0.72 & 0.77 & 0.78 & 0.65 & 0.66 \\
\hline & $\mathrm{P}$ & 0.39 & 0.21 & 0.75 & 0.57 & 0.31 & 0.05 & 0.98 & 0.21 & 0.13 & $0.00 *$ & \\
\hline \multirow[t]{6}{*}{ JX } & $N_{\mathrm{A}}$ & 4 & 15 & 12 & 26 & 8 & 5 & 12 & 12 & 8 & 8 & 11.0 \\
\hline & $N_{\mathrm{E}}$ & 2.5 & 10.1 & 5.5 & 16.7 & 3.4 & 4.5 & 5.2 & 4.7 & 5.1 & 6.4 & 6.41 \\
\hline & $H_{\mathrm{O}}^{E}$ & 0.47 & 0.97 & 0.80 & 0.67 & 0.68 & 0.67 & 0.75 & 0.90 & 0.68 & 0.83 & 0.74 \\
\hline & $H_{\mathrm{E}}$ & 0.60 & 0.91 & 0.83 & 0.95 & 0.71 & 0.79 & 0.81 & 0.80 & 0.81 & 0.85 & 0.80 \\
\hline & PIC & 0.51 & 0.89 & 0.80 & 0.94 & 0.67 & 0.75 & 0.78 & 0.76 & 0.78 & 0.83 & 0.77 \\
\hline & $\mathrm{P}$ & $0.01 *$ & 0.35 & 0.29 & 1.00 & $0.04 *$ & $0.02 *$ & 0.89 & 0.36 & $0.01 *$ & $0.00 *$ & \\
\hline \multirow[t]{6}{*}{ HN } & $N_{\mathrm{A}}$ & 5 & 21 & 10 & 27 & 11 & 8 & 13 & 15 & 12 & 11 & 13.3 \\
\hline & $N_{\mathrm{E}}^{\mathrm{A}}$ & 3.0 & 11.6 & 6.0 & 16.0 & 7.6 & 4.7 & 6.6 & 7.7 & 4.3 & 5.5 & 7.3 \\
\hline & $H_{\mathrm{O}}$ & 0.67 & 0.97 & 0.85 & 0.87 & 0.83 & 0.72 & 0.62 & 0.84 & 0.65 & 0.92 & 0.79 \\
\hline & $H_{\mathrm{E}}$ & 0.67 & 0.92 & 0.84 & 0.95 & 0.88 & 0.80 & 0.86 & 0.88 & 0.78 & 0.82 & 0.83 \\
\hline & PIC & 0.62 & 0.91 & 0.81 & 0.93 & 0.85 & 0.76 & 0.83 & 0.86 & 0.75 & 0.79 & 0.81 \\
\hline & P & $0.04 *$ & 1.00 & 0.23 & 1.00 & 0.06 & 0.14 & $0.04 *$ & 0.93 & 0.30 & 0.08 & \\
\hline \multirow[t]{6}{*}{ ZJ } & $N_{\mathrm{A}}$ & 5 & 17 & 11 & 23 & 13 & 6 & 14 & 13 & 10 & 11 & 12.3 \\
\hline & $N_{\mathrm{E}}^{n}$ & 3.1 & 7.5 & 5.4 & 14.2 & 9.0 & 4.6 & 6.1 & 6.5 & 6.0 & 9.6 & 7.2 \\
\hline & $H_{\mathrm{O}}$ & 0.67 & 0.97 & 0.75 & 0.88 & 0.87 & 0.83 & 0.77 & 0.92 & 0.88 & 0.82 & 0.83 \\
\hline & $H_{\mathrm{E}}$ & 0.68 & 0.87 & 0.82 & 0.94 & 0.90 & 0.79 & 0.84 & 0.85 & 0.84 & 0.90 & 0.84 \\
\hline & PIC & 0.61 & 0.85 & 0.79 & 0.93 & 0.88 & 0.75 & 0.82 & 0.83 & 0.81 & 0.89 & 0.82 \\
\hline & $\mathrm{P}$ & 0.58 & 0.85 & 0.69 & 1.00 & 0.29 & 0.22 & 0.98 & 0.99 & 0.27 & 0.16 & \\
\hline
\end{tabular}

$N_{\mathrm{A}}=$ number of alleles; $N_{\mathrm{E}}=$ number of effective alleles; $H_{\mathrm{E}}=$ expected heterozygosity; $H_{\mathrm{O}}=$ observed heterozygosity; $\mathrm{PIC}=$ polymorphism information content. * Significant difference $(\mathrm{P}<0.05)$.

Bottleneck analysis was conducted using the Bottleneck software under the twophrased model of mutation (TPM) of microsatellites. $\mathrm{P}>0.05$ indicates that the population has not experienced a recent bottleneck. According to the sign test, population JX deviated from mutation-drift equilibrium and experienced a recent bottleneck (Table 4).

Table 4. Analysis of the possibility of a recent bottleneck using sign tests in the four Channa argus populations.

\begin{tabular}{lcc}
\hline Population & \multicolumn{2}{c}{ TPM } \\
\cline { 2 - 3 } & $H_{\mathrm{E}} / H_{\mathrm{D}}$ & $\mathrm{P}$ \\
\hline $\mathrm{SD}$ & $5 / 5$ & 0.40 \\
$\mathrm{JX}$ & $6 / 4$ & 0.61 \\
$\mathrm{HN}$ & $9 / 1$ & 0.04 \\
ZJ & $8 / 2$ & 0.16 \\
\hline
\end{tabular}

TPM = two-phrased model of mutation. $H_{\mathrm{E}} / H_{\mathrm{D}}=$ ratio of number of individuals with heterozygosity excesses to the number with heterozygosity deficiency. $\mathrm{P}>0.05$ indicates that the population has not experienced a recent bottleneck.

\section{Population genetic differentiation}

Pairwise genetic differentiations based on allele frequency were determined for the 
four cultured stocks of $C$. argus (Table 5). All pairwise $F_{\mathrm{ST}}$ was statistically significant $(\mathrm{P}<$ $0.05)$. The highest differentiation occurred between populations HN and SD (0.028), while the lowest differentiation observed was between populations JX and HN (0.100). Similarly, the greatest distances were observed between populations HN and SD, whereas the smallest distances were obtained between populations HN and JX. The phylogenetic tree was constructed by UPGMA using the MEGA5 software (Figure 1). AMOVA of microsatellites revealed that the variation within individuals, between individuals within populations, and between populations was $90.85,3.57$ and $5.58 \%$, respectively (Table 6).

Genetic clustering analysis using the Structure program indicated that the number of genetic clusters was three $(\mathrm{K}=3$; Figure 2$)$. The four stocks were divided into three potential populations. Populations ZJ and HN were assigned to the same genetic background, suggesting that they may share the same origin (represented in green in Figure 2).

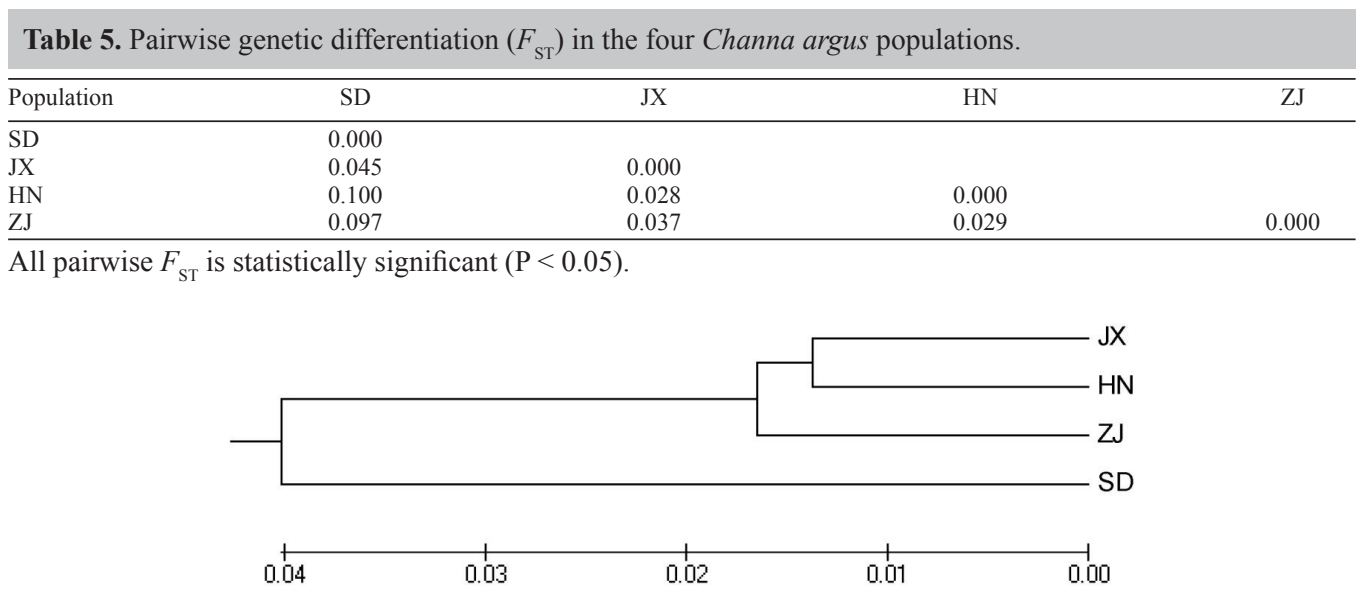

Figure 1. UPGMA molecular trees based on genetic distance of four Channa argus populations.

Table 6. AMOVA of microsatellite in four populations of Channa argus.

\begin{tabular}{lccr}
\hline Source of variation & Sum of squares & Variance components & Percentage of variance \\
\hline Among populations & 96.67 & 0.23 & 5.58 \\
Among individual within populations & 970.45 & 0.15 & 3.57 \\
Within individuals & 915.45 & 3.81 & 90.85 \\
Total variation & 1982.12 & 4.41 & 100.00 \\
\hline
\end{tabular}

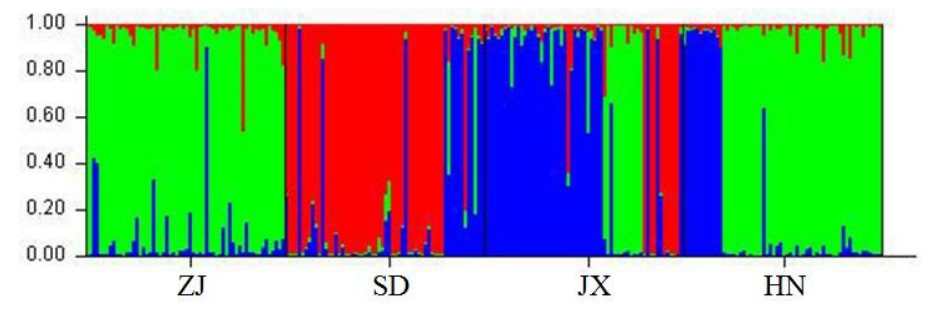

Figure 2. Structure version 2.3.1 analysis of Channa argus populations using microsatellite genotype data from 10 microsatellite loci (the inferred clusters, $\mathrm{K}=3$ ). 


\section{DISCUSSION}

Genetic variation is the basis of a selective breeding program. In past few years, many popular genetic makers were used for assessing genetic variation in selective breeding programs (Liu and Cordes, 2004), such as mitochondrial DNA, and SSR. Due to many advantages, microsatellites as genetic markers have been extensively used in genetic diversity studies in fish species (Shimoda et al., 1999; Aguilar and Garza, 2006; Narum et al., 2006; Sekino and Hara, 2007). In this study, we constructed a partial genomic DNA enriched for AC- and TGmicrosatellites with six primers designed here, and four primers designed by the sequence of NCBI for studying genetic variation and relationships of four cultured populations of C. argus. Among them, the primer $C H M 9$ was designed by the sequence of Channa maculate and showed high polymorphism in the four C. argus populations. All 10 microsatellites were found highly polymorphic. Highly polymorphic loci provided better estimates of genetic distances than less polymorphic loci (Kalinowski, 2002). In comparison to the published microsatellites of $C$. argus (Wen and Sun, 2010), these 10 microsatellite loci seemed to be much more polymorphic in terms of allele number. Several factors may account for this difference, such as the repeat length of microsatellites may be different. Normally, a longer repeat microsatellite shows higher polymorphism (Goldstein and Schlotterer, 1999). Thus, allele number is usually positively associated with the sample size (Goldstein and Schlotterer, 1999). Compared with the wild snakehead populations (Zhuo et al., 2012), the average $H_{\mathrm{E}}$ in these four cultured populations varied from 0.70 to 0.84 while the average $H_{\mathrm{E}}$ in those eight wild populations ranged from 0.70 to 0.85. Compared with other freshwater species (DeWoody and Avise, 2000), it indicated that C. argus has high allelic diversity. Actually, breeding methods inevitably influence the genetic variability of any farmed population (Romana-Eguia et al., 2004). Normally, cultured populations contain lower genetic diversity than wild populations as indicated by previous research (Norris et al., 1999). However, due to no regulation system in breeding program in China, fish farmers have been using wild snakehead as parents to produce offspring. The high diversity in cultured snakehead fish populations may be good news for fish breeders.

It is important to determine whether the population had experienced a recent bottleneck, because bottlenecks can increase demographic stochasticity, loss of genetic variation, rates of inbreeding and fixation of mildly deleterious alleles, thereby reducing evolutionary potential and increasing the probability of population extinction (Frankel and Soule, 1981; Lande, 1988; Ralls et al., 1988; Hedrick and Miller, 1992; Jimenez et al., 1994; Mills and Smouse, 1994). In the present study, the JX population was shown to have experienced a small bottleneck, which indicates that the genetic variability of the population is expected to decline rapidly. One explanation could be that the JX samples were collected from a cohort based on a small number of parent fish. However, as soon as population size becomes larger, it starts to increase owing to new mutations (Nei et al., 1975). When population size is restored, the average number of alleles per locus increases faster than the average heterozygosity. In other words, it is necessary to increase effective population sizes in the JX population for better breeding.

The $F_{\mathrm{ST}}$ value and AMOVA are useful measurements of genetic differentiation among populations. The analysis of pairwise genetic differentiation revealed that the $F_{\mathrm{ST}}$ values ranged from 0.028 to 0.100 , which was in line with a moderate level of genetic differentiation (Hartl and Clark, 1997). Based on microsatellite genotypes, the UPGMA-phylogenetic tree showed that JX and HN were the nearest clusters while HN and SD showed the farthest 
genetic distance. This clustering result is related to their geographic distribution distance. The relativity between geographic isolation and genetic distance shows that the genetic differentiations between populations are mainly because of the geographic proximity (Li et al., 2007). AMOVA revealed that genetic variation within individuals was $90.85 \%$, and the genetic variation between populations was $5.58 \%$, which suggested a moderate level of genetic differentiation. These different degrees of differentiation between populations and the variations in populations were mainly attributed to genetic drift and gene flow or the diffuseness between populations (Wright, 1978). Future studies are aimed at understanding whether the crosses between fishes from different populations will generate hybrid vigor.

The present study focused only on four cultured snakehead fish populations subjected to a supportive breeding program. High genetic diversity was detected in these four snakehead fish populations, which could provide the basis for future breeding program. This study demonstrates a strong indication of reduced effective numbers of breeders in the JX population. Thus, attention should be paid to routine genetic monitoring of breeding activities and to identifying whether there is a decrease in the effective population sizes of the snakehead fish.

\section{ACKNOWLEDGMENTS}

Research supported by the Shanghai University Knowledge Service Platform (\#ZF1206). We acknowledge the help of Narayan P. Pandit for improving the English of the manuscript.

\section{REFERENCES}

Aguilar A and Garza JC (2006). A comparison of variability and population structure for major histocompatibility complex and microsatellite loci in California coastal steelhead (Oncorhynchus mykiss Walbaum). Mol. Ecol. 15: 923-937.

Amanov AA (1974). Morphology and mode of life of the Amur snakehead (Ophiocephalus argus warpachowskii) in Chimkurgan reservoir. J. Ichthyol. 14: 713-717.

Begg GA and Waldman JR (1999). An holistic approach to fish stock identification. Fish. Res. 43: 35-44.

Botstein D, White RL, Skolnick M and Davis RW (1980). Construction of a genetic linkage map in man using restriction fragment length polymorphisms. Am. J. Hum. Genet. 32: 314-331.

Courtenay WR and Williams JD (2004). Snakeheads (Pisces, Channidae) - A Biological Synopsis and Risk Assessment. U.S. Department of the Interior, U.S. Geological Survey Circular.

DeWoody JA and Avise JC (2000). Microsatellite variation in marine, freshwater and anadromous fishes compared with other animals. J. Fish. Biol. 56: 461-473.

Dukravets GM and Machulin AI (1978). The morphology and ecology of the Amur snakehead, Ophiocephalus argus warpachowskii, acclimatized in the Syr Dar'ya Basin. J. Ichthyol. 18: 203-208.

Evanno G, Regnaut S and Goudet J (2005). Detecting the number of clusters of individuals using the software STRUCTURE: a simulation study. Mol. Ecol. 14: 2611-2620.

Excoffier L, Laval G and Schneider S (2005). Arlequin (version 3.0): an integrated software package for population genetics data analysis. Evol. Bioinform. Online 1: 47-50.

Frankel OH and Soule ME (1981). Conservation and Evolution. Cambridge University Press, Cambridge.

Goldstein DB and Schlotterer C (1999). Microsatellites: Evolution and Applications. Oxford University Press, Oxford.

Guo QL, Jia WZ, Han XP, Cai TZ, et al. (2004). Rickettsia-like organism infection in a freshwater cultured fish Ophiocephalus argus C. in China. Prog. Nat. Sci. 14: 417-422.

Hartl DL and Clark AG (1997). Principles of Population Genetics. Sinauer Associates, Sunderland.

Hedrick PW and Miller PS (1992). Conservation genetics: techniques and fundamentals. Ecol. Appl. 2: 30-46.

Jimenez JA, Hughes KA, Alaks G, Graham L, et al. (1994). An experimental study of inbreeding depression in a natural habitat. Science 266: 271-273.

Kalinowski ST (2002). How many alleles per locus should be used to estimate genetic distances? Heredity 88: 62-65.

Lande R (1988). Genetics and demography in biological conservation. Science 241: 1455-1460. 
Lewis PO and Zaykin D (2000). Genetic Data Analysis. Available at [http://hydrodictyon.eeb.uconn.edu/people/plewis/ software.php]. Accessed October 10, 2012.

Li D, Kang D, Yin Q, Sun X, et al. (2007). Microsatellite DNA marker analysis of genetic diversity in wild common carp (Cyprinus carpio L.) populations. J. Genet. Genomics 34: 984-993.

Li SW and Yang HQ (1998). Status and prospect of Channa argus culture in China. Mod. Fish. Info. 13: 6-8.

Liu F, Xia JH, Bai ZY, Fu JJ, et al. (2009). High genetic diversity and substantial population differentiation in grass carp (Ctenopharyngodon idella) revealed by microsatellite analysis. Aquaculture 297: 51-56.

Liu ZJ and Cordes JF (2004). DNA marker technologies and their applications in aquaculture genetics. Aquaculture 238: 1-37.

Lo LC and Yue GH (2008). Microsatellites for broodstock management of the Tiger grouper, Epinephelus fuscoguttatus. Anim. Genet. 39: 90-91.

Mills SL and Smouse PE (1994). Demographic consequences of inbreeding in remnant populations. Am. Nat. 144: 412431.

Narum SR, Powell MS, Evenson R and Sharp B (2006). Microsatellites reveal population substructure of Klickitat River native steelhead and genetic divergence from an introduced stock. North Am. J. Fish. Manage. 26: 147-155.

Nei MN, Maruyama T and Chakraborty R (1975). The bottleneck effect and genetic variability in populations. Evolution 29: $1-10$

Norris AT, Bradley DG and Cunningham EP (1999). Microsatellite genetic variation between and within farmed and wild Atlantic salmon (Salmo salar) populations. Aquaculture 180: 247-264.

Pritchard JK, Stephens M and Donnelly P (2000). Inference of population structure using multilocus genotype data. Genetics 155: 945-959.

Ralls K, Ballou JD and Templeton A (1988). Estimates of lethal equivalents and the cost of inbreeding in mammals. Conserv. Biol. 2: 185-193.

Romana-Eguia MRR, Ikeda M, Basiao ZU and Taniguchi N (2004). Genetic diversity in farmed Asian Nile and red hybrid tilapia stocks evaluated from microsatellite and mitochondrial DNA analysis. Aquaculture 236: 131-150.

Sambrook J and Russell DW (2001). Molecular Cloning: A Laboratory Manual. 3rd edn. Cold Spring Harbor Laboratory Press, Cold Spring Harbor.

Sekino M and Hara M (2007). Linkage maps for the Pacific abalone (genus Haliotis) based on microsatellite DNA markers. Genetics 175: 945-958.

Shimoda N, Knapik EW, Ziniti J, Sim C, et al. (1999). Zebrafish genetic map with 2000 microsatellite markers. Genomics 58: 219-232.

Tautz D and Renz M (1984). Simple sequences are ubiquitous repetitive components of eukaryotic genomes. Nucleic Acids Res. 12: 4127-4138.

Wen XX and Sun XW (2010). Isolation and screening of microsatellite makers from Argus snakehead fish Channa argus. J. Dalian Ocean Univ. 26: 260-264.

Wright (1978). Evolution and the Genetics of Populations. University of Chicago Press, Chicago.

Yang C, Zhu X and Sun X (2008). Development of microsatellite markers and their utilization in genetic diversity analysis of cultivated and wild populations of the mud carp (Cirrhina molitorella). J. Genet. Genomics 35: 201-206.

Zhu L, Xie N, Zhu SR, Li ZQ, et al. (2011). Analysis of culture characteristics of F1 hybrids from different combinations of Channa maculate (ㅇ) x C. argus (ठ). Freshwater Fish. 41: 81-84.

Zhuo X, Liang R, Chen Y, Huang G, et al. (2012). Genetic characterization of northern snakehead (Channa argus) populations in China using microsatellite markers. Biochem. Syst. Ecol. 43: 25-31. 